\title{
THE IMPACT OF TYPICAL RECOVERY PRACTICE USED IN OVERSOLD ROOM ON TURKISH GUESTS
}

\author{
Vedat İyitoğlu ${ }^{1}$ \\ G. Nilüfer Tetik ${ }^{2}$
}

\begin{abstract}
A significant number of accommodation companies overbook in order to maximize their revenue especially during the peak periods. However, overbooking is a risky activity that may bring companies face to face with the problem of overselling rooms. In such a situation of overselling rooms, hotels usually transfer their guests to other hotels having similar quality as a typical recovery practice. In this study, it is aimed to explore the possible impacts of this practice on Turkish guests' satisfactions and revisit intentions.

The data of the study was collected through a scenario-based questionnaire in Mersin in the period of May-June, 2014. By using snowball and convenience sampling methods, the researchers reached 116 valid questionnaires in total.

As a result of the study, it was understood that the typical recovery practice had a tragic impact on Turkish guests. The results especially indicated that the participants' revisit intentions were relatively much more affected, causing very few of them to revisit intentions. On the other hand, less experience and younger participants were found to react in a statistically more positive manner to such transfer activities. Depending on the findings it is suggested that the hotels' managers who have guests mostly from the Turkish market be more careful about overbooking practice. Additionally, if such transfers are inevitable, they are recommended to start with the youngest guests who have least experiences of vacation.
\end{abstract}

Key words: Overbooking, Oversold, Guest Satisfaction, Revisit Intention, Turkish Guests, Hotels

\section{INTRODUCTION}

On the purpose of avoiding possible revenue loss due to from early check outs, late cancellations and no shows, many hotels overbook and as a result they come up against the risk of oversold. In the case of the oversold, some guests are usually transferred to other comparable hotels as a recovery. Some previously studies have indicated that recovery efforts carried out in the significant service failure have low effects on the guests (Hoffman and Chung, 1999, p. 77; Suskind, 2005, p. 150; Mount, 2012, p. 155). Hence the oversold and the recovery might have serious effects causing guest losses. So the effects of recovery efforts on the guest behaviors must be explored.

Because the service failures from overbooking are the kinds of conscious failures that are intended and foreseeable, they differ from other service failures. So accommodation companies take advantage on the oversold in comparison with other failures. Because in such failures hotels have an opportunity to make a choice in advance about such issues as which guests will walked and which recovery strategies will be used to what extent. On the other hand, on the study related to service failures and service recovery, it has been revealed that the customer's reaction may change depending on such factors as some demographic features, experience and culture (Hwang and Wen, 2009, p. 662). Within this context, the effects of oversold and recovery on the guests are expected to be different, as well. So on the service failure due to overbooking, guests who will have relatively more

\footnotetext{
${ }^{1}$ Lecturer, Anamur Vocational School, Mersin University, Mersin, Turkey.

${ }^{2}$ Professor, Faculty of Tourism, Akdeniz University, Antalya, Turkey.
} 
positive reactions should be chosen as walk for preventing the guests' negative reactions or at least minimizing that.

Although there are limited study conducted on the effects of oversold and recovery on the guests in the international literature, it has not been possible to reach any study about the reactions of Turkish guests. The basic reason is that it is connected with the size of the domestic tourism market. However, the number of Turkish tourist has significantly increased in recent years and it has made progress over $100 \%$ in ten years. Thus, it is indicated that the rate of Turkish tourist increase 15\% in the hotels in Antalya and 30\% and even at times $40 \%$ in Bodrum (TÜRSAB, 2014). On the other hand, narrowing depending on some reasons in foreign markets such as Germany, Russia and Ukraine makes domestic holiday market more important in terms of hotels. So it is expected that Turkish tourists walked because of oversold. Within this context, the purpose of the study is to determine the effect of the typical recovery activity applied in oversold on the Turkish guests' satisfaction and return intention and to explore the relation between these two variables.

First of all, the information about overbooking, oversold and service recovery is given on the study. Then sample, data collection and analysis process have been explained under the name of the method. After that the findings have been presented and the study hypothesis has been tested. On the last part, the conclusions have been summarized and some suggestions have been made for the next studies.

\section{LITERATURE REVIEW}

\section{Overbooking and Oversold}

Overbooking is old and common in accommodation industry to increase the room revenue (Rothstein, 1974, p. 389; Toh, 1985, p. 24). In the most general sense, this application is described as accepting more reservation than certain or available capacity in a period (Noone and Lee, 2011, p. 350).

The accommodation companies like the other ones overbook to avoid possible revenue loss by maximizing the usage of their capacity. Because the service can not be stored, when even one of the rooms is empty, it is thought as nonrecoverable revenue loss. When accommodation companies take reservation as much as the number of available room, they may come up against the risk of empty rooms. That's why some guests may cancel their reservations before arrival date. On the other hand, it is possible that some reservations do not take place even if they are not cancelled. The hotel managers considering these kinds of negative situations prefer taking more reservation. It is possible to increase company revenue $2 \%$ and $5 \%$ by effective overbooking application (Wangenheim and Bayon, 2007, p. 36). Overbooking in accommodation company is so common that it is stated that these rates may vary between 5\% and 13\% internationally (Gökdeniz and Dinç, 2011, p. 243). While overbooking is described as a means of useful yield management, it is also thought as a risky application whose results are very costly. The most important risk of this application is to turn overbooking into oversold. In the event that a hotel is overbooked resulting in no rooms remaining available, hotel management will often "walk" the customer to a neighboring hotel at an equal or complimentary rate depending on the situation. It is identified as a serious service failure in terms of the guests (Levesque and McDougall, 2000, p. 33; Wangenheim and Bayon, 2007, p. 43; Noone and Lee, 2011, p. $335)$. 
In the previous studies, overbooking is classified as serious service failures related to the product (Zhu, Sivakumar and Parasuraman, 2004, p. 494; Lee, Singh and Chan, 2011, p. 199). The most important reason of the guest loss is this kind of service failure. Many studies have shown that the guests who have come up against such service failures as overbooking do not return (Ennew and Schoefer, 2003, p. 12; Wangenheim and Bayon, 2007, p. 43; Noone and Lee, 2011, p. 350; Chuang, Cheng, Chang and Yang, 2012, p. 259; Mount, 2013, p. 94). Within this context, the most important cost related to the overbooking applications is the loss of guests. Because finding a new guest is harder and more costly than keeping the available one (Hoffman and Kelley, 2000, p. 419; Lee, Singh and Chan 2011, p. 197). The researchers claims that the cost of gaining a new guest is three-five times (Hoffman and Chung,1999, p. 72) and even six-seven times (Hisaka, 2013) more than keeping the available guest. So keeping the guest or at least having lowlevel guest loss must be considered as an important goal.

\section{Service Recovery}

Even if it is not service failure, accommodation companies may avoid the loss from the guests which service failures cause (Michel, 2001, p. 20; Mount, 2012, p. 160). It is possible with the clear, basic and effective service recovery efforts defined as basically "replacing the truth with the fault" (Mattila, 1999, p. 284; Ennew and Schoefer, 2003, p. 2; Mount and Mattila, 2009, p. 302). During the application, any activities to solve the service failures, to convert negative reactions of the guests who are not satisfied to positive and as a result to keep the guests are thought as a part of service recovery (Lewis and McCann, 2004, p. 7).

The typical recovery activities used in case of the service failures because of overbooking by the hotels are generally composed of supportive services such as free accommodation, transportation, and telephone call (Hwang and Wen, 2009, p. 660; Noone and Lee, 2011, p. 335). This is a standard application especially used by pioneer hotels. However, in order to satisfy their guests, in recent years accommodation companies have presented such extra compensations as free accommodation for the next seasons, extra promotions and some payment (Noone and Lee, 2011, p. 336). For the companies the topic that must be considered is the effects of recovery efforts on guests' reactions and behaviors. Because the effects of these recoveries may be under the expected level. In that case while the losses of the guests occur, the direct cost increases.

The guest satisfaction may increase with the effective service recovery and accordingly the guest losses may decrease (Lewis and McCann, 2004, p. 7; DeTienne, Seawright and Brough, 2005, p. 2). However, there are so many studies whose literature has shown that service recovery results are not satisfactory enough (Mattila, 1999, p. 284; Kuenzel and Katsaris, 2011, p. 20; Mount, 2012, p. 155). For instance, while a study has shown that the guest return is only $41 \%$ as a result of the most common service recovery applications (Hoffman and Chung, 1999, p. 77), another study has indicated that only $28 \%$ of the restaurant guests return (Suskind, 2005, p. 150). Although these results, it's claimed that there was significant and linear correlation between service recovery and customers' intent to return (Noone and Lee, 2011, p. 345; Mount, 2012, p. 161). That's why when costumers perceive recovery efforts of a company as positive; their intent to return can increase.

The impact of the service failure and recovery strategies on guests may vary depending on culture. For instance, according to a study conducted in restaurant sector in the USA and 
Ireland, it was found out that the recovery expectations of American customers are further (Mueller, Palmer, Mack and McMullan, 2003, p. 395). According to another study conducted with the participants from the USA, Singapore and Australia by Wong (2004, p. 957), it was found that service recovery improves service perception in each three sample but there is a positive impact about purchase intention only on Americans. Therefore, it is expected that the impact of the similar service failure and recovery strategies on Turkish guests is different. As a result, the main hypothesis of the study "H1. There is a meaningful relation between the guest satisfaction and their return intentions in the result of typical recovery application."

The service recovery may change depending on such factors as the type of the service, the importance of the failure, the aim of purchase, the guests' experience and the expectations of service recovery (Lewis and McCann, 2004, p. 9; DeTienne, Seawright and Brough, 2005 , p. 2). On the other hand, even the companies in the similar activity surroundings may differ in market qualities, cost structure, service concept and management abilities. So it is expected that the similar service failure and the recovery activities may differ from the company to company (Zhu, Sivakumar and Parasuraman, 2004, p. 516).

Many factors such as gender, reservation time, accommodation period and who pays may affect the sense of justice of the guests related to the overbooking policy (Hwang and Wen, 2009, p. 662). McColl-Kennedy, Dausv and Sparks (2003, p. 66) found that there were significant differences between male and female respondents regarding their perceptions of how service recovery should be handled. Women want their views heard during service recovery attempts and to be allowed to provide input. Men, in contrast, do not view voice as important. In this context another hypotheses have been enhanced as follows;

H2a. The effect on Turkish guests satisfaction of the typical recovery strategy used in overbooking varies depending on gender.

H2b. The effect on Turkish guests' return intention of the typical recovery strategy used in overbooking varies depending on gender.

Many studies have claimed that there is a relation between guest reaction and age in service failure (Gyung Kim, Wang \& Mattila, 2010, p. 981). As A result of the study conducted by Varela-Neira and the others $(2010$, p. 40$)$, it was found that older guests are, less negative feelings are. The study on service failure and recovery strategies conducted in banking sector in Greece resulted that the old participants have more expectations about recovery (Lewis \& Spyrakopoulos, 2001, p. 44).Thus, the following hypotheses were suggested.

H3a. The effect on Turkish guests satisfaction of the typical recovery strategy used in overbooking varies depending on age.

H3b. The effect on Turkish guests' return intention of the typical recovery strategy used in overbooking varies depending on age.

According to the study conducted by Chuang and the others (2012, p. 258), it is found out that the service recovery activity may vary depending on service failure experience. Within this context, the guests who experienced the failure are more sensitive to the recoveries. Therefore, experienced guests overreact when there is a failure or recovery activity. 
According to another study, it is claimed that the guests who have more perceived value are more tolerant to the failures and are more open to the recoveries (Zhu, Sivakumar and Parasuraman, 2004, p. 499). It is thought that the guests who have more experience can witness more service failure related to overbooking. Within this context, the last hypotheses of the study are;

H4a. The effect on Turkish guests satisfaction of the typical recovery strategy used in overbooking varies depending on the holiday experience.

H4b. The effect on Turkish guests' return intention of the typical recovery strategy used in overbooking varies depending on the holiday experience.

\section{METHODOLOGY}

The data has been collected with a scenario based survey applied to the participants who have had experiences before in 2014 May-September in Mersin-Anamur. The scenarios are considered as one of the most important measuring means especially used in the studies about the service failures (Hwang and Wen, 2009, p. 666). The scenario introduced to the participants in applying the survey in which the convenience and the snowball sampling methods are used is like this;

"You have made a certain reservation for a week in a 4 or 5 star hotel. However, when you arrived the hotel, the front office staff said that the hotel is totally full and there is no available room. So you were transferred to another hotel in near surrounding that has similar standards with free transportation."

When TUIK (2014) the household tourism statistics are analyzed, it has been seen that the average number of stay overnight between 2009 and 2014 is at least 8 days. Thus, the holiday period in the scenario has been stated as a week. In the case of the occurrence of the situation in the scenario, in order to determine the satisfaction of the participants, a scale with three items and whose answer categories have been ranked as seven likert (1. dissatisfied - 7. satisfied) has been used. In order to determine the participants' return intentions, another scale with two items and whose answer categories have been ranked as seven likert (1.disagree - 7.agree) has been used. Both scales have been taken from the study done by Noone and Lee (2011, p. 343).

\section{RESULTS}

The data has been collected from the participants who have had experiences in 4 or 5 star hotels by the questionnaire. The data about the participants of the survey has been shown in the Tab. 1 . 
Tab. 1. Some Features of Participants

\begin{tabular}{crrlrrr}
\hline Gender & $\mathbf{n}$ & $\mathbf{\%}$ & Age & $\mathbf{n}$ & $\mathbf{\%}$ \\
\hline Female & 38 & 32,8 & $20-30$ years old & 21 & 20,0 \\
\hline Male & 78 & 67,2 & $31-40$ years old & 44 & 41,9 \\
\hline Total & 116 & 100 & $41-50$ years old & 34 & 32,4 \\
\hline Marital status & $\mathbf{n}$ & $\mathbf{\%}$ & $51+$ & 6 & 5,7 \\
\hline Single & 6 & 5,6 & Total & 105 & 100,0 \\
\hline Married & 102 & 94,4 & $\mathbf{4 - 5 *}$ hotels experience & $\mathbf{n}$ & $\mathbf{\%}$ \\
\hline Total & 108 & 100,0 & $1-2$ times & 41 & 38,0 \\
\hline Child & $\mathbf{n}$ & $\mathbf{\%}$ & $3-4$ times & 36 & 33,3 \\
\hline Yes & 83 & 77,2 & $5-6$ times & 23 & 21,3 \\
\hline No & 18 & 17,8 & $7+$ & 8 & 7,4 \\
\hline Total & 101 & 100,0 & Total & 108 & 100,0 \\
\hline
\end{tabular}

As it is seen in Tab. 1, most of the participants are married $(94,4 \%)$ and male $(67,2 \%)$, and have children $(77,2 \%)$. According to age distribution, it is seen that while the participants are mostly between 31 and 40 (about $43 \%$ ), the ones who are over 51 are the fewest. On the other hand, most of the participants have had experiences in a 4 or 5 star hotel only once or twice (38\%). It is possible to consider this data as an important indicator of the progress of the domestic holiday market.

Before the tests of the hypothesis of the study, the reliability tests of the scales of the guest satisfaction and the return intentions have been done. As a result of the analysis made using alpha, reliability co-efficient of the satisfactory scale consisted of three items has been determined as $\alpha=.898$ and the scale of the guests return intention consisted of two items has been determined as $\alpha=.735$. These rates show that test results are quite reliable (Kalayc1, 2008, p. 405).

The explanatory factor analysis has been applied in order to determine the construct validity of the scales used in the study. According to the result of the analysis, the guest satisfactory scale was found $\mathrm{p}<0,001$, Kaiser-Meyer-Olkin (KMO) sampling rate in significance level was found 0,706 and the result of the test of Barlett was found 224,527.

The EFA result of return intention scales was found to be significant at $p<0,001$ level and KMO sampling rate was found 0,500 while Barlett test result was found 71,886. Kaiser (1974) claims that the rate of KMO must be at least 500 for the factor analysis (Hair and others, 1998, p. 99). Within this context, while the satisfaction scale is good for the factor analysis, return scale is acceptable for it.

The result of the satisfaction scale factor analysis showed that the data were collected in one factor and the variation explained in one factor was $\% 83,057$. As a result of the factor analysis of the return intention scale, the variation explained similarly was found as $\% 84,249$. The impact of the application of transferring to other hotels in case of oversold on guest satisfaction and return intention was shown in Tab. 2 and the relation between these variations was shown in Tab. 3 .

According to the factor analysis of the satisfaction scale, the data were collected in one factor and the variation explained in one factor was $\% 83,057$. As a result of the factor analysis of the return intention scale, the variation explained similarly was found as $\% 84,249$.

The impact of the application of transferring to other hotels in case of oversold on guest satisfaction and return intention was shown in Tab. 2 and the relation between these 
variations was shown in Tab. 3. As it is seen in Tab. 2, the Turkish participants have found the recovery activities in case of oversold mostly dissatisfactory ( $\bar{X}=2,27$ ). In addition, return intentions have been affected more and it has been seen to be at lower level ( $\overline{\mathrm{X}}=$ $1,55)$.

It supports that the results of the service recovery in the literature are not effective (Mattila, 1999, p. 284; Kuenzel and Katsaris, 2011, p. 20; Mount, 2012, p. 155. However, the Turkish guests bear cost overrun relatively. Many Turkish guests spend a lot of money and time for holiday. Thus, they have more expectations for holiday and they are affected more by the service failure (Lewis and McCann, 2004, p. 9; DeTienne, Seawright and Brough, 2005 , p. 1)... As a result, the service recovery activity has almost no impact on the Turkish guests. According to this result, it is advised to manager to use less costly applications in oversold.

Tab. 2. The Potential Effects of the Typical Recovery Application on Turkish Guests

\begin{tabular}{lccccc}
\hline & $\mathrm{n}$ & Minimum & Maximum & Mean & $\begin{array}{c}\text { Std. } \\
\text { Deviation }\end{array}$ \\
\hline Guest satisfaction & 116 & 1,00 & 4,00 & 2,2701 &, 96400 \\
\hline Satisfaction & 116 & 1,00 & 3,00 & 1,5474 &, 59336 \\
\hline
\end{tabular}

According to the Tab. 3, it is seen that there is a positive and significant relation between the satisfaction and the return intention of the guests transferred to the other hotels $(\mathrm{r}=$ $0,798 ; \mathrm{p}<.01)$. As a result, $\mathrm{H} 1$ was supported. In other words, the possibilities of the guest loss significantly increase with the typical recovery activity.

Tab. 3. The Relation between Guest Satisfaction and Return Intention $(n=116)$

\begin{tabular}{llll}
\hline & & $\mathbf{1}$ & $\mathbf{2}$ \\
\hline 1. Satisfaction & $\begin{array}{l}\text { Pearson } \\
\text { Correlation }\end{array}$ & 1 \\
\cline { 2 - 3 } & Sig. (2-tailed) & \\
\hline 2. Return Intention & $\begin{array}{l}\text { Pearson } \\
\text { Correlation }\end{array}$ &, $798^{* *}$ & 1 \\
\cline { 2 - 3 } & Sig. (2-tailed) &, 000 \\
\hline
\end{tabular}

**. Correlation is significant at the 0.01 level (2-tailed).

As it is understood in the table above, transferring the guests to the other hotels as a result of oversold just supports a shot-term company profit. Nevertheless the losses of the guests increase in long-term and the company profit is affected negatively. Thus accommodation companies falling short must apply more creative recovery activities in order to avoid the losses of the guests.

The study conducted by Noone and Lee (2011, p. 345) has shown that a little payment in addition to recovery activities may increase the guest satisfaction but there is not a meaningful effect on the return intention. Therefore transferring the guests who affect the company less instead of over recovery activities may be an important strategy. Within this 
context it is advised to transfer the guests who affect the company profit least to the other hotels when the hotel falls short.

Independent two samples t-test was administered to determine if there are significant differences between the satisfaction and return intentions of the participants in terms of gender. As a result of the test, it was found that the average of the satisfaction $(\bar{x}=2,10)$ and the return intention $(\overline{\mathrm{X}}=1,43)$ of the females is lower than the males $(\overline{\mathrm{X}}=2,35$ and $\overline{\mathrm{X}}$ $=1,60)$. However, these differences have not been supported statistically $(\mathrm{t}=-1,359 ; \mathrm{p}>.05$ and $\mathrm{t}=-1,441 ; \mathrm{p}>.05)$. So $\mathrm{H} 2 \mathrm{a}$ and $\mathrm{H} 2 \mathrm{~b}$ have not been accepted.

The ANOVA results applied to determine the varieties depending on age and holiday experience that are the other hypothesis of the study are shown in the table below.

Tab. 4. The Effect of the Typical Service Recovery According to Gender and Holiday Experience

\begin{tabular}{|c|c|c|c|c|c|c|c|}
\hline & Age Group & $\mathbf{n}$ & $\overline{\mathrm{x}}$ & S.S. & $\mathbf{F}$ & $p$ & Difference \\
\hline \multirow{3}{*}{ Satisfaction } & $\begin{array}{l}1 \text { ( } 20-30 \text { years } \\
\text { old) }\end{array}$ & 21 & 2,5714 & ,93180 & 5,795 &, 004 & 1 and $2>3$ \\
\hline & $\begin{array}{l}2(31-40 \text { years } \\
\text { old) }\end{array}$ & 44 & 2,3258 & 1,06746 & & & \\
\hline & $3(41+)$ & 40 & 1,8167 &, 65350 & & & \\
\hline \multirow{4}{*}{$\begin{array}{l}\text { Return } \\
\text { Intention }\end{array}$} & $\begin{array}{l}1 \text { (20-30 years } \\
\text { old) }\end{array}$ & 21 & 1,6429 & ,55097 & 5,819 & ,004 & 1 and $2>3$ \\
\hline & $\begin{array}{l}2(31-40 \text { years } \\
\text { old })\end{array}$ & 44 & 1,6705 & ,64649 & & & \\
\hline & $3(41+)$ & 40 & 1,2750 & ,46616 & & & \\
\hline & $\begin{array}{c}\text { Experience } \\
\text { Group }\end{array}$ & $\mathbf{n}$ & $\overline{\mathrm{X}}$ & s.s. & $\mathbf{F}$ & $p$ & Difference \\
\hline \multirow{3}{*}{ Satisfaction } & 1 (1-2 times) & 41 & 2,7154 & ,85167 & 10,167 & 000 & 1 and $2>3$ \\
\hline & 2 (3-4 times) & 36 & 2,3704 & ,92506 & & & \\
\hline & $3(5+)$ & 31 & 1,7849 & ,82349 & & & \\
\hline \multirow{3}{*}{$\begin{array}{l}\text { Return } \\
\text { Intention }\end{array}$} & 1 (1-2 times) & 41 & 1,7927 & ,60183 & 6,430 & ,002 & $1>3$ \\
\hline & 2 (3-4 times) & 36 & 1,5833 & ,59161 & & & \\
\hline & $3(5+)$ & 31 & 1,3065 & ,49459 & & & \\
\hline
\end{tabular}

As it is seen in the Tab. 4, the satisfaction and the return intention of the participants vary depending on age $(\mathrm{F}=5,795 ; \mathrm{p}<.01$ and $\mathrm{F}=5,819 ; \mathrm{p}<.01)$. Accordingly, in case of being transferred to another hotel, the satisfaction $(\overline{\mathrm{X}}=1,82)$ and the return intentions $(\overline{\mathrm{X}}=1,28)$ of the potential guests who are 41 and over are statistically lower than the other age groups. Thus, the older they are, the less satisfaction and return intention are. In that case, $\mathrm{H} 3 \mathrm{a}$ and $\mathrm{H} 3 \mathrm{~b}$ hypothesis the study have been supported. It is thought that older guests stay the course of holiday and so they are affected much more by the negative situations. In this sense, in case of oversold, it is advised to address initially younger guests. It is found out that according to the comparison in terms of experience, the satisfaction and the return intention of the guests who are experienced in holiday are significantly lower. So H4a and $\mathrm{H} 4 \mathrm{~b}$ have been similarly supported and accepted. The number of the Turkish guests transferred to other hotels because of overbooking can be expected to be less due to the size of the domestic holiday market. Therefore, especially the reactions of the guests who 
experienced the same situation in their previous holiday may be more severe. When these results are evaluated together, it is understood that the older guests who are more experienced in holiday are more responsive to the recoveries applied in oversold.

\section{CONCLUSION}

Most of the accomodation companies overbook for income maximization and therefore face the risk of oversold. In case of oversold, the companies transfer their guests to other hotels as a standart recovery activity. The result of this study indicates that the application may have strong negative effects. As a result of the study, the impact of the recovery activities commonly applied by hotels on the guests' satisfaction and the return intention is lower than expected. It has an impact on bussiness profit in two ways. Within this context, they lose their guests and also the costs increase because the sources are not used effectively. So, firstly the hotel managers should make an effort not to oversold. In case of oversold, it is possible to decrease the loss of income caused by the loss of guests. Within this context, first of all, when the income contribution of the guests is considered, those who have less contribution must be initially transferred. On the other hand, as a result of the study, the guests who have less holiday experience and who are younger react more positively. Hence, it is advised to transfer those guests to other hotels in case the hotel oversold. It is possible for the hotels that do not overbook to fall short because of failure, repeated reservation, mis-reservation and some reasons caused by a guest or the hotel, as well. Therefore, the result of the study is important not only for the accomodation companies overbooking but also for those falling short.A study conducted using the detailed interview technique by Kuenzel and Katsaris (2011, p. 20) has explored that managers and tourists do not have the same opinion about the service failure and recovery. Thus, the managers of the accomodation companies must develop a more customercentered point of view to find effective recovery strategies in oversold. Although similar data collection method has been exceedingly used in the literature, the most important limitation of the study is to acquire the data from the participants who do not actually have any service failures.

On the other hand, based on the methods of the sampling, the data collected from the limited target population are open to discussion in terms of representation of the population. So similar studies may be conducted by collecting tha data especially from the guests who have experienced service failure related to overbooking before and from the available guests of the hotels. Beside it is thought that the studies in which the absolute data instead of the comparative one is used are necessary to evaluate service recovery applications in terms of the hotels. It is possible to explain the rate of each recovery activity with the mathematical formulas including such data as the cost of the sources, the impact on the customers, the risk (the risk of vacancy and/or compensation because of not serving, the risk of paying reklamation). In accomodation companies and food and beverage companies, although there are similar service recovery strategies, different activity ratio may occur (Hoffman and Kelly, 2000, p. 422).. Therefore, the studies can be conducted comparatively in different service sectors, different accomodation companies and different customer groups. It is claimed that the service failures must be recovered as soon as possible. Because it is thought that the negative attitudes of the customers will increase when it is too late. However, another idea claims that applying the service recovery after a while instead of immediately will give better results. The guests who have experienced the failure may be calm, behave logically and think positively about the 
recovery efforts of the company in the course of te time. Within this context, the reactions of the guests may be explored more meaningfully with the help of the evaluations especially before and after standard recovery application. Because the services in the hotels where the guests transferred to may be below or beyond expectations, the reaction of the guest may vary.

\section{REFERENCES}

1. Chuang, S. C., Cheng, Y. H., Chang, C. J., and Yang, S. W. (2012). "The Effect Of Service Failure Types and Service Recovery On Customer Satisfaction: A Mental Accounting Perspective", The Service Industries Journal, 32(2), 257-271.

2. DeTienne, K. B., Seawright, K.K. and Brough, A. R. (2005). "Cost-Effective Service Recovery Knowing Which Customers to Keep”, International Journal of Applied Marketing, 1(3), 1-22.

3. Ennew, C and Schoefer, K. (2003). Service Failure and Service Recovery in Tourism: A Review, Christel DeHaan Tourism and Travel Research Institute, Nottingham University Business School.

4. Gökdeniz, A. and Dinç, Y. (2011). Konaklama İşletmelerinde Önbüro Operasyonları ve Yönetimi (7. Bask1). Ankara: Detay Yayıncılık.

5. Gyung Kim, M., Wang, C., \& Mattila, A. S. (2010). "The Relationship Between Consumer Complaining Behavior And Service Recovery: An Integrative Review", International Journal of Contemporary Hospitality Management, 22(7), 975-991

6. Hair, J. F., Anderson, R. E., Tatham, R. L., \& William, C. Black (1998), Multivariate Data Analysis (5. Edition) New Jersey: Pearson Education.

7. Hisaka, A. (2013). The Cost of Bad Customer Service. http://about.americanexpress.com/news/pr/2011/csbar.aspx, (01.02.2014).

8. Hoffman, K. D. and Chung, B. G. (1999). "Hospitality Recovery Strategies: Customer Preference versus Firm Use", Journal of Hospitality \& Tourism Research, 23(1), 71-84.

9. Hoffman, K. D. and Kelley, S. W. (2000). "Perceived Justice Needs And Recovery Evaluation: A Contingency Approach", European Journal of Marketing, 34( 3/4), 418-432.

10. Hwang, J., and Wen, L. (2009). "The Effect of Perceived Fairness toward Hotel Overbooking and Compensation Practices on Customer Loyalty", International Journal of Contemporary Hospitality Management, 21(6), 659-675.

11. Kaiser, H. F., \& Rice, J. (1974). "Little Jiffy, Mark IV", Educational and Psychological Measurement, 34(1), 111-117.

12. Kalayc1, Ş. (2008). SPSS Uygulamalı Çok Değişkenli İstatistik Teknikler (3. Baskı). Ankara: Asil Yayın Dağıtım.

13. Kuenzel, S. and Katsaris, N. (2011). "Discrepancies Between Tourists' and Managers' Perceptions of Service Failures and Service Recoveries In Hotels", International Journal Of Business Research, 11(5), 16-25.

14. Lee, M. J., Singh, N. and Chan, E. S. W. (2011). "Service Failures And Recovery Actions In The Hotel Industry: A Text-Mining Approach", Journal of Vacation Marketing 17(3), 197-207.

15. Levesque, T. J., and Mcdougall, G. H. (2000). "Service Problems And Recovery Strategies: An Experiment", Canadian Journal of Administrative Sciences, 17(1), 20-37. 
16. Lewis, B.R. \& Mccann, P. (2004), "Service Failure And Recovery: Evidence From The Hotel Industry", International Journal Of Contemporary Hospitality Management, 16(1), 6-17.

17. Lewis, B. R., \& Spyrakopoulos, S. (2001). Service Failures And Recovery In Retail Banking: The Customers' Perspective. International Journal Of Bank Marketing, 19(1), 37-48.

18. Mattila, A.S. (1999). "An Examination of Factors Affecting Service Recovery in a Restaurant Setting”, Journal of Hospitality \& Tourism Research, 23(3), 284-298.

19. Mccoll-Kennedy, J. R., Daus, C. S., \& Sparks, B. A. (2003). The Role of Gender in Reactions to Service Failure and Recovery. Journal of Service Research, 6(1), 66-82.

20. Michel, S. (2001). "Analyzing Service Failures And Recoveries: A Process Approach", International Journal Of Service Industry Management, 12(1), 20-33.

21. Mount, D. J. (2012). "Putting the Dollar Signs on Quality: The Benefits of Service Recovery in the Hotel Industry", Journal of Quality Assurance in Hospitality \& Tourism, 13(2), 152-163.

22. Mount, D. J. (2013). "Putting the Dollar Signs on Quality: The Cost of Experienced Problems in the Hotel Industry". International Journal of Hospitality \& Tourism Administration, 14(1), 87-97

23. Mount, D. J. and Mattila, A (2009). "The Relationship of Reliability and Recovery to Satisfaction and Return Intent at the Hotel Unit Level", Journal of Quality Assurance in Hospitality \& Tourism, 10(4), 301-310.

24. Mueller, R. D., Palmer, A., Mack, R., \& Mcmullan, R. (2003). "Service In The Restaurant Industry: An American and Irish Comparison of Service Failures and Recovery Strategies", International Journal of Hospitality Management, 22(4), 395-418.

25. Noone, B. M. (2012). "Overcompensating For Severe Service Failure: Perceived Fairness And Effect On Negative Word-Of-Mouth Intent", Journal Of Services Marketing, 26(5), 342-351.

26. Noone, B. M. and Lee, C.H. (2011). "Hotel Overbooking: The Affect of Overcompensation on Customers' Reactions to Denied Services", Journal of Hospitality \& Tourism Research, 35(3), 334-357.

27. Rothstein, M. (1974). "Hotel Overbooking As A Markovian Sequential Decision Process", Decision Sciences, 5(3), 389-404.

28. Suskind, A. (2005). "A Content Analysis of Consumer Complaints, Remedies, and Repatronage Intentions Regarding Dissatisfying Service Experiences". The Journal of Hospitality and Tourism Research, 29(2), 150-169.

29. Toh, R. (1985). "An Inventory Depletion Overbooking Model for the Hotel Industry", Journal of Travel Research, 23(4), 24-30.

30. TÜIKK (2014). Hanehalk1 Yurtiçi Turizm İstatistikleri. http://www.tuik.gov.tr/PreTablo.do?alt id=1072 (16.03.2015).

31. TÜRSAB (2014). Türsab 2014 Turizm Sezonu Raporu. http://www.tursab.org.tr/dosya/12187/tursab-2014-turizm-sezonuraporu_12187_5495404.pdf (17.11.2014).

32. Varela-Neira, C., Vázquez-Casielles, R., \& Iglesias, V. (2010). "The Effects of Customer Age and Recovery Strategies in A Service Failure Setting”, Journal of Financial Services Marketing, 15(1), 32-48 
33. Wangenheim, F. V. and Bayon, T. (2007). "Behavioral Consequences of Overbooking Service Capacity", American Marketing Association, 71(4), 36-47.

34. Wong, N. Y. (2004). "The Role of Culture in the Perception of Service Recovery", Journal of Business Research, 57(9), 957-963.

35. Zhou, Y., Tsang, A. S., Huang, M., \& Zhou, N. (2014). Does Delaying ServiceFailure Resolution Ever Make Sense? Journal of Business Research, 67(2), 159166.

36. Zhu, Z., Sivakumart, K. and Parasuraman, A. (2004). "A Mathematical Model of Service Failure and Recovery Strategies”, Decision Sciences, 35(3), 493-525. 